\title{
Eating patterns - temporal distribution, converging and diverging foods, meals eaten inside and outside of the home - implications for developing FBDG
}

\author{
JM Kearney ${ }^{1, *}$, KFAM Hulshof ${ }^{2}$ and M Gibney ${ }^{1}$ \\ 'Institute of European Food Studies, Trinity College, Dublin, Ireland: ${ }^{2}$ TNO Nutrition and Food Research Institute, \\ Department of Nutritional Epidemiology, Zeist, The Netherlands
}

\begin{abstract}
Objective: A consideration of eating patterns in the general population is necessary when deriving food-based dietary guidelines (FBDG) as promoting the intake of one food may indirectly result in the increased consumption of another, which may not always be desirable. A number of issues that influence meal patterns such as temporal distribution of food intake (using data from the Netherlands), converging and diverging foods (using data from Ireland) and meals eaten inside and outside of the home (using data from the UK) are examined and discussed in the context of developing FBDG.

Setting: Food intake databases from three EU countries: The Netherlands, Ireland and the UK.

Results: The hot meal (dinner) was found to be the main contributor to the intake of energy and macro-nutrients in the Dutch population. It was also the main contributor to the intake of all micro-nutrients with the exception of calcium where the bread meal contributed a similar proportion as the hot meal to the intake of this micronutrient. Furthermore, fruit intake showed a very different temporal distribution to vegetable intake. Exploring the convergence of certain foods in the Irish population also revealed differences between fruit and vegetables. A low correlation was shown for consumers of fruit and vegetables indicating that being a high fruit consumer did not suggest being also a high vegetable consumer. An examination of where meals were consumed among British adults showed that $71 \%$ of all meals were consumed inside the home while $29 \%$ were consumed outside. $27 \%$ of food energy and $45 \%$ of alcohol energy was consumed out of home by the total population. In addition, those eating less of their foods out of home obtained a lower proportion of their food energy from fat and protein and a higher proportion from carbohydrate. A different demographic profile was associated with eating out compared to eating in, comprising more males and younger individuals.

Conclusions: Information on patterns of food intake and food habits, specifically temporal distribution, the convergence and divergence of foods and foods consumed inside and outside of the home, give a culturally specific picture of food consumption practices within a population. This should enable the development of more culturally acceptable and realistic FBDG.
\end{abstract}

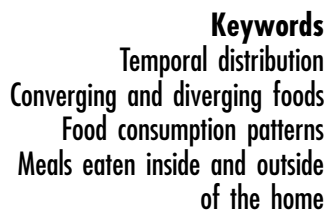

\section{Introduction}

In order for food-based dietary guidelines (FBDG) to be attainable, it is necessary to take account of the cultural context in which they are being developed ${ }^{1}$. A consideration of the cultural context with respect to food consumption in a population covers not only eating patterns in terms of what foods are commonly or rarely consumed (either in the diet as a whole or together within meals) but also, when they are consumed and where they consumed. To gather such information it is necessary to have detailed data on the temporal distribution of the diet (daily) and location of consumption. In contrast, the time frame of the impact of the diet on public health with respect to energy and nutrients has a long-term character. This means that the assessment of diet-health relationships should take the habitual diet as the starting point. This will integrate the within product and within subject variation over a sufficiently long time period. However, from the perspective of nutrition education this is not a 
very practical situation since it leads to statements like 'there are no good or bad products' as it is the total diet consumed during a long period of time that may be classified as 'healthy' or 'unhealthy'. For nutrition education, the formulations should be as precise and concrete as possible. A more specific picture of the cultural practices with regard to food consumption may be given if a knowledge is obtained of what foods tend to converge within a diet or within a meal, of where they are consumed and at what point in the day they are commonly consumed. This might even imply that meal patterns on separate days should be taken into account. In this paper, temporal distribution, convergence/divergence of foods, and where foods are consumed (inside/ outside of the home) in the context of developing FBDG are examined individually.

\section{Temporal distribution}

\section{Aims and rationale}

The aim of this exercise was to examine the consumption of food groups by meal and the intake of energy and nutrients by meal. Such an exercise enables the examination of the relationship between foods and nutrients within different eating occasions. It is known that there is considerable variation during the day as to the dietary quality of the separate meals. This variation is due to differences in food consumption, whereby food products may have their typical times of consumption.

\section{Methods and results}

More detailed results of this work have been published already by TNO as report numbers V 98.809 and V $98.810^{2,3}$ based on the third Dutch National Food
Consumption Survey (DNFCS). This survey was conducted among a representative sample of the noninstitutionalised Dutch population in 1997-1998. Approximately 6,000 participants recorded all foods and beverages consumed per meal in two consecutive days. According to the Dutch eating patterns, six eating occasions were distinguished, namely: breakfast, during the morning (snack am), lunch (bread meal as noon or evening meal), during the afternoon (snack pm), dinner (hot meal as evening or noon meal), during the evening and night (snack evening). The results shown in Tables 1 and 2 are for the total population. The main contribution to the intake of energy and macro-nutrients in this population comes from the hot meal (dinner) (Table 1). The hot meal is also the main contributor to the intake of all micro-nutrients with the exception of calcium, where the bread meal contributed a similar proportion as the hot meal to the intake of this micro-nutrient. While over two thirds of haem iron $(71 \%)$ is obtained from the hot meal, just one third of non-haem iron is provided by this meal. The contribution of meals (\%) to the consumption of various food groups is shown in Table 2. A greater variety in contribution by different meals to food groups is evident when compared with the contribution to energy and nutrients. While potatoes, vegetables and legumes are mainly obtained from the hot meal (98\%, 93\% and 98\% respectively), fruit reveals a distinctly different pattern. The hot meal contributes less than a quarter of fruit intake, about the same level as the afternoon snack. Indeed, the other two snacks (in the morning and in the evening) also contribute substantially to fruit intake. Thus, in the Dutch population, fruit intake shows a very different temporal distribution to vegetable intake. Such information may be useful when developing food-based

Table 1 Contribution (as \%) of meals to the intake of energy and nutrients

\begin{tabular}{|c|c|c|c|c|c|c|}
\hline & Breakfast & Snack (am) & Lunch (bread meal) & Snack (pm) & Dinner (hot meal) & Snack (evening) \\
\hline Energy (kJ) & 13 & 7 & 22 & 9 & 35 & 14 \\
\hline Protein (total) (g) & 12 & 4 & 25 & 5 & 46 & 7 \\
\hline Protein (animal) (g) & 10 & 4 & 23 & 4 & 53 & 6 \\
\hline Protein (vegetable) (g) & 16 & 6 & 29 & 7 & 32 & 10 \\
\hline Fat (total) (g) & 11 & 6 & 23 & 7 & 41 & 12 \\
\hline Saturated fatty acid (g) & 12 & 6 & 23 & 8 & 40 & 11 \\
\hline Monounsaturated fatty acid (g) & 9 & 5 & 21 & 8 & 43 & 13 \\
\hline Polyunsaturated fatty acid (g) & 14 & 5 & 27 & 5 & 39 & 10 \\
\hline Cholesterol (mg) & 11 & 5 & 27 & 6 & 44 & 8 \\
\hline Carbohydrate (g) & 15 & 9 & 22 & 12 & 28 & 14 \\
\hline Dietary fibre $(\mathrm{g})$ & 14 & 7 & 23 & 7 & 41 & 8 \\
\hline Calcium (mg) & 18 & 8 & 29 & 7 & 28 & 10 \\
\hline Phosphorus (mg) & 15 & 6 & 27 & 6 & 36 & 10 \\
\hline Iron (mg) & 14 & 7 & 23 & 7 & 40 & 10 \\
\hline Haem iron (mg) & 3 & 2 & 18 & 2 & 71 & 4 \\
\hline Non-haem iron (mg) & 16 & 9 & 24 & 8 & 33 & 11 \\
\hline Zinc (mg) & 13 & 4 & 25 & 5 & 46 & 7 \\
\hline Vitamin $\mathrm{B}_{1}(\mathrm{mg})$ & 11 & 5 & 23 & 5 & 49 & 7 \\
\hline Vitamin $B_{2}(\mathrm{mg})$ & 15 & 7 & 25 & 7 & 36 & 10 \\
\hline Vitamin $B_{6}(\mathrm{mg})$ & 9 & 4 & 17 & 7 & 51 & 11 \\
\hline Vitamin $D(\mu \mathrm{g})$ & 15 & 5 & 32 & 5 & 37 & 6 \\
\hline Vitamin E (mg) & 14 & 5 & 25 & 6 & 41 & 9 \\
\hline Vitamin C (mg) & 10 & 6 & 11 & 10 & 51 & 12 \\
\hline
\end{tabular}


Table 2 Contribution (as \%) of meals to the consumption of a number of food groups

\begin{tabular}{|c|c|c|c|c|c|c|}
\hline & Breakfast & Snack (am) & Lunch (bread meal) & Snack (pm) & Dinner (hot meal) & Snack (evening) \\
\hline Cereal products \& binding agents & 7 & 0 & 2 & 0 & 90 & 1 \\
\hline Bread & 29 & 6 & $5 \overline{7}$ & 3 & 3 & 2 \\
\hline Pastries \& cakes & 4 & 28 & 4 & 29 & 1 & 34 \\
\hline Sugar, sweets, sweet fillings \& sauces & 26 & 14 & 17 & 20 & 6 & 7 \\
\hline Nuts, seeds \& snacks & 2 & 4 & 16 & 15 & 25 & 38 \\
\hline Potatoes & 0 & 0 & 1 & 0 & 98 & 1 \\
\hline Vegetables & 0 & 0 & 5 & 1 & 93 & 1 \\
\hline Legumes & 1 & 0 & 1 & 0 & 98 & 0 \\
\hline Fruit & 8 & 13 & 17 & 23 & 24 & 15 \\
\hline Cheese & 20 & 5 & 47 & 4 & 13 & 10 \\
\hline Milk \& milk products & 20 & 8 & 28 & 6 & 29 & 8 \\
\hline Soups & 0 & 2 & 30 & 4 & 62 & 2 \\
\hline Savoury sandwich fillings & 37 & 5 & 52 & 2 & 2 & 2 \\
\hline Ready-made dishes & 0 & 0 & 9 & 3 & 85 & 2 \\
\hline Eggs & 17 & 1 & 39 & 1 & 40 & 2 \\
\hline Fish & 1 & 1 & 29 & 5 & 61 & 4 \\
\hline Meat, meat products \& poultry & 3 & 1 & 15 & 1 & 76 & 3 \\
\hline Alcoholic drinks & 0 & 2 & 1 & 19 & 12 & 66 \\
\hline Non-alcoholic drinks & 16 & 20 & 9 & 23 & 7 & 26 \\
\hline
\end{tabular}

dietary guidelines and it also would be interesting to see to what extent the temporal differences in fruit and vegetable intake in the Dutch population are reflected in other EU member states.

In looking at temporal distribution it should be realised that there are many different calculation methods, and all these methods are correct when used for the correct question. For instance, in the DNFCS 1997-1998, 95\% of the total population consumed a breakfast, 96\% a lunch, 99\% a hot meal, whereas the proportion of consumers of in-between meals was $94 \%$ during the morning and evening and 97\% during the afternoon (two-day period). Table 3 shows how the fat content of a meal and the contribution to daily intake hardly differ when the calculations are performed excluding the non-users of that specific meal. However, the impact (of non-users) will increase with a growing number of meal skippers and will affect especially the calculations based on energy \%. For instance, in the DNFCS-3 among males aged 19-22 yrs. $12 \%$ skipped breakfast and $7 \%$ skipped lunch. For the total group $(n=130)$ the fat content of breakfast and lunch was 13 and $28 \mathrm{~g}$ fat per day, respectively. For consumers only the fat content of breakfast and lunch increased by $2 \mathrm{~g} /$ day. Fat intake expressed as energy \% rose from 25.9 (total group) to 29.6 (users only) for breakfast and from 36.2 (total group) to 38.9 (users only) for lunch.

\section{Converging and diverging foods}

\section{Rationale}

In addition to temporal distribution, there are a number of other methodological issues of potential importance in the development of food-based dietary guidelines. These include convergence and divergence of foods, foods eaten inside and outside of the home, meal patterns in terms of convergence of foods within meals. To date, little or no in-depth research has been carried out to-date in the way different foods converge within meals. Convergence and divergence of foods, and foods eaten inside and outside of the home are two aspects of meal patterns which are discussed below.

The analysis of patterns of converging and diverging food intakes has numerous applications such as food fortification, stochastic modelling for exposure assessment to food chemicals, and epidemiological analysis of diet and disease as well as the development of food based dietary guidelines. Convergence and divergence of food intakes may be examined at different levels of aggregation (for example convergence between the food group

Table 3 Mean total fat intake (g/day) and average contribution to moment of consumption and calculation method

\begin{tabular}{|c|c|c|c|c|}
\hline & \multicolumn{2}{|c|}{$\begin{array}{l}\text { Mean intake (g/day) } \\
\text { Non-users of the meal }\end{array}$} & \multicolumn{2}{|c|}{$\begin{array}{l}\text { Contribution (\%) } \\
\text { Non-users of the meal }\end{array}$} \\
\hline & Incl. & Excl. & Incl. & Excl. \\
\hline Breakfast & 10 & 11 & 11 & 12 \\
\hline Lunch & 21 & 22 & 23 & 25 \\
\hline Dinner (hot meal) & 36 & 36 & 41 & 40 \\
\hline Snack (am) & 5 & 5 & 6 & 6 \\
\hline Snack (pm) & 6 & 7 & 7 & 6 \\
\hline Snack (evening) & 10 & 11 & 12 & 11 \\
\hline
\end{tabular}


'total bread' and butter and between 'brown bread' and butter). It may also be explored for the total population or among consumers only of both foods (e.g. conditional correlations).

\section{Methods}

There are many ways to examine the patterns of convergence and divergence among foods and these will depend largely on the structure of the database as well as the purpose for which the results will be used. Here, just two approaches are examined (i) conditional correlations using Pearson correlations and (ii) two-bytwo tables of the lowest and highest tertiles of food intake. The results have been analysed using some measure of correlation, which can be derived from a two-by-two table such as a chi-square $\left(\chi^{2}\right)$ and phicoefficient $\phi(-1 \leq \phi \leq 1)$. The food intake data used in this exploratory analysis came from the Irish National Nutrition Survey (INNS) conducted in 1990 ${ }^{4}$. The method of food intake measurement was a 7-day diet history.

\section{Results}

Conditional correlations between a number of foods and food groups are shown in Table 4. The correlations are conditional as they refer only to those subjects who are consuming both foods. In this particular selection of foods, the strongest correlations were found for consumers of butter and potatoes, white bread and butter, and savoury snacks and soft drinks. In contrast, there was a poor correlation for consumers of fruit and vegetables. Further differences in the consumption patterns of fruit and vegetables were evident in that, while the correlations between consumers of butter and vegetables (both

Table 4 Conditional correlations between butter, white bread, savoury snacks, fruit and several food groups among Irish adults

\begin{tabular}{|c|c|c|c|c|}
\hline & Foods & $\begin{array}{l}\text { Pearson } \\
\text { correlations }\end{array}$ & (n) & Significance \\
\hline \multirow[t]{8}{*}{ Butter } & Veg. (total) & $0.211^{\star \star *}$ & 393 & $<0.0001$ \\
\hline & Veg. (leafy) & $0.293^{* * *}$ & 314 & $<0.0001$ \\
\hline & Veg. (root) & 0.123 * & 335 & 0.025 \\
\hline & Fruit (total) & -0.084 & 321 & 0.135 \\
\hline & Fruit (pomme) & 0.112 & 262 & 0.070 \\
\hline & Fruit (citrus) & -0.098 & 181 & 0.188 \\
\hline & Fruit (juice) & -0.055 & 93 & 0.602 \\
\hline & Potatoes (total) & $0.365^{* * *}$ & 388 & $<0.0001$ \\
\hline \multirow[t]{10}{*}{ White bread } & Cheese & 0.203 * & 146 & 0.014 \\
\hline & Milk (full-fat) & 0.209 *** & 506 & $<0.0001$ \\
\hline & Butter & $0.542^{* * *}$ & 315 & $<0.0001$ \\
\hline & Fruit (total) & -0.018 & 409 & 0.716 \\
\hline & Veg. (total) & 0.082 & 499 & 0.067 \\
\hline & Veg. (leafy) & $0.197^{\star \star \star}$ & 393 & $<0.0001$ \\
\hline & Red meat & $0.212^{\star \star *}$ & 452 & $<0.0001$ \\
\hline & Fish & 0.037 & 317 & 0.509 \\
\hline & Savoury snacks & 0.086 & 191 & 0.235 \\
\hline & Soft drinks & 0.092 & 253 & 0.143 \\
\hline \multicolumn{5}{|l|}{ Savoury } \\
\hline Snacks & Soft drinks & $0.440 * \star *$ & 143 & 0.000 \\
\hline Fruit (total) & Veg. (total) & 0.069 & 555 & 0.106 \\
\hline
\end{tabular}

total and leafy) were highly significant and convergent, the relationship between butter and fruit (total) was very weak and tended to be divergent.

Another approach to examining the patterns of convergence and divergence between foods was by determining the proportion of subjects in the lowest and highest tertiles of food ' $x$ ' (e.g. fruit) among those in the lowest and highest tertiles of food ' $y$ ' (e.g. vegetables). An analysis of the food groups fruit and vegetables was carried out in both adults and children (age 8-18 years) where both the total population and consumers only data were used to determine the tertiles of intake (Table 5). The influence of gender on the convergence and divergence of fruit and vegetables was also examined. Using total population or consumer only data there was no convergence between vegetable and fruit intakes among adults. Among children, however, the convergence was significant when consumer only data was used but not total population data. Similarly, differing results emerged depending on whether total population or consumer only data was used for females but not for males. Among adult females, an individual in the lowest tertile of intake of vegetables was more than twice as likely to be in the lowest tertile of intake of fruit as in the highest tertile of intake of fruit, when the total population intake data were used. While adult females in the lowest vegetable tertile were also more likely to be in the lowest fruit tertile compared to the highest fruit tertile using consumer only data, the relationship was not significant. This preliminary exploration of convergence/divergence between vegetables and fruit intake using tertiles emphasises the need for further research to determine the most appropriate ways of examining convergence between foods. It also highlights the differences between population sub-groups (e.g. young or old consumers, males and females) on patterns of convergence and divergence between foods. The data would also tend to suggest that it might not necessarily be appropriate to put fruit and vegetables together in single messages promoting an increase in their consumption. A similar conclusion was reached by Trudeau et al. (1998) $)^{5}$ from a cross-sectional study in the US, suggesting that separate targeted interventions are necessary for fruit and vegetables. A similar conclusion might also be reached based on the temporal distribution analysis of fruit and vegetable consumption in the Netherlands (Table 2).

\section{Meals eaten in and out of the home}

\section{Rationale and metbods}

An increasing proportion of all meals is being consumed out of home. The possibility arises that the food intake patterns and nutrient intakes associated with eating out of home may differ significantly from those eaten in the home. Information on such patterns of intake, particularly for target nutrients of public health significance such as 
Table 5 Two-by-two tables of vegetables and fruit tertiles among adults, children, males and females in the Irish population (total population and consumers only)

\begin{tabular}{|c|c|c|c|c|c|c|}
\hline & & \multicolumn{2}{|c|}{ Total population. Vegetable tertiles } & & \multicolumn{2}{|c|}{ Consumers only. Vegetable tertiles } \\
\hline & & Lowest & Highest & & Lowest & Highest \\
\hline Adults (18yrs.+) & & & $\%$ & & & \\
\hline Fruit tertiles & $\begin{array}{l}\text { Lowest } \\
\text { Highest } \\
\chi^{2}=2.482\end{array}$ & $\begin{array}{l}37 \\
28 \\
\phi=0.104\end{array}$ & $\begin{array}{l}33 \\
38 \\
\text { NS }\end{array}$ & $\chi^{2}=0.084$ & $\begin{array}{l}28 \\
26 \\
\phi=0.028\end{array}$ & $\begin{array}{l}26 \\
27 \\
\text { NS }\end{array}$ \\
\hline $\begin{array}{l}\text { Young ( }<18 \text { yrs.) } \\
\text { Fruit tertiles }\end{array}$ & $\begin{array}{l}\text { Lowest } \\
\text { Highest } \\
x^{2}=2.914\end{array}$ & $\begin{array}{l}42 \\
27 \\
\phi=0.245\end{array}$ & $\begin{array}{l}32 \\
37 \\
\text { NS }\end{array}$ & $\chi^{2}=4.53$ & $\begin{array}{l}28 \\
22 \\
\phi=0.214\end{array}$ & $\begin{array}{l}17 \\
32 \\
\text { Sig }\end{array}$ \\
\hline $\begin{array}{l}\text { Adult males } \\
\text { Fruit tertiles }\end{array}$ & $\begin{array}{l}\text { Lowest } \\
\text { Highest } \\
\chi^{2}=1.16\end{array}$ & $\begin{array}{l}30 \\
35 \\
\phi=0.113\end{array}$ & $\begin{array}{l}21 \\
39 \\
\text { NS }\end{array}$ & $x^{2}=0.023$ & $\begin{array}{l}30 \\
21 \\
\phi=0.014\end{array}$ & $\begin{array}{l}31 \\
23 \\
\text { NS }\end{array}$ \\
\hline $\begin{array}{l}\text { Adult females } \\
\text { Fruit tertiles }\end{array}$ & $\begin{array}{l}\text { Lowest } \\
\text { Highest } \\
\chi^{2}=6.46\end{array}$ & $\begin{array}{l}49 \\
21 \\
\phi=0.219\end{array}$ & $\begin{array}{l}31 \\
33 \\
\text { Sig }\end{array}$ & $\chi^{2}=1.57$ & $\begin{array}{l}31 \\
19 \\
\phi=0.120\end{array}$ & $\begin{array}{l}29 \\
29 \\
\text { NS }\end{array}$ \\
\hline
\end{tabular}

total fat, saturated fat and dietary fibre, may be useful when developing food-based dietary guidelines.

\section{Data and results}

Using data from the 'Dietary and Nutritional Survey of British Adults' (Gregory et al. 1990) ${ }^{6}$ patterns of energy and nutrient intake between in and out of home consumption were examined. The survey consisted of a

Table 6 The \% of the total sample eating in and out of home at different time periods and by the demographic factors (sex and age groups) among British adults ${ }^{7}$

\begin{tabular}{|c|c|c|c|c|c|c|c|c|}
\hline \multirow[b]{3}{*}{ Time } & \multicolumn{8}{|c|}{ Age group (years) } \\
\hline & \multicolumn{2}{|c|}{$16-25$} & \multicolumn{2}{|c|}{$26-45$} & \multicolumn{2}{|c|}{$45-55$} & \multicolumn{2}{|c|}{$56-65$} \\
\hline & Home & Out & Home & Out & Home & Out & Home & Out \\
\hline & \multicolumn{8}{|c|}{$\%$} \\
\hline $0.00-4.30 \mathrm{am}$ & 54 & 46 & 57 & 43 & 52 & 48 & 89 & 11 \\
\hline $4.30-5$ & 83 & 17 & 88 & 12 & 92 & 8 & 95 & 5 \\
\hline $9.00-11.45 \mathrm{am}$ & 49 & 51 & 56 & 44 & 60 & 40 & 74 & 26 \\
\hline $11.45-2.15 \mathrm{pm}$ & 40 & 60 & 52 & 48 & 56 & 44 & 70 & 30 \\
\hline $2.15-5.00 p m$ & 53 & 47 & 57 & 43 & 62 & 38 & 75 & 25 \\
\hline $5.00-8.00 \mathrm{pm}$ & 82 & 18 & 84 & 16 & 90 & 10 & 92 & 8 \\
\hline $8.00-12.00 \mathrm{pm}$ & 59 & 41 & 71 & 29 & 74 & 26 & 83 & 17 \\
\hline
\end{tabular}

\begin{tabular}{|c|c|c|c|c|c|c|}
\hline \multirow[b]{2}{*}{ Time } & \multicolumn{2}{|c|}{ Total sample } & \multicolumn{2}{|c|}{ Males } & \multicolumn{2}{|c|}{ Females } \\
\hline & Home & Out & Home & Out & Home & Out \\
\hline & & & $\%$ & & & \\
\hline $0.00-4.30 \mathrm{am}$ & 60 & 40 & 54 & 46 & 69 & 31 \\
\hline $4.30-9.00 \mathrm{am}$ & 90 & 10 & 86 & 14 & 94 & 6 \\
\hline $9.00-11.45 \mathrm{am}$ & 60 & 40 & 50 & 50 & 67 & 33 \\
\hline $11.45-2.15 \mathrm{pm}$ & 54 & 46 & 45 & 55 & 63 & 37 \\
\hline $2.15-5.00 \mathrm{pm}$ & 61 & 39 & 53 & 47 & 67 & 32 \\
\hline $5.00-8.00 p m$ & 87 & 13 & 84 & 16 & 89 & 11 \\
\hline 8.00-12.00pm & 72 & 28 & 67 & 33 & 77 & 23 \\
\hline
\end{tabular}

7-day weighed intake on 2,197 British adults, 16-64 years of age. The definition of eating out in this survey was taken to include all items consumed away from home regardless of whether they were prepared in or out of home $^{7}$. In terms of all meals consumed, $71 \%$ were consumed inside the home while $29 \%$ were consumed outside. $27 \%$ of food energy and $45 \%$ of alcohol energy was consumed out of home by the total population.

The times at which people most commonly consumed food outside versus inside the home and how this was influenced by demographic characteristics such as sex and age group is shown in Table $6^{7}$. Meals consumed between 11.45 am and 2.15 pm was the most likely time the total sample ate outside the homes. Males were much more likely to eat their lunch time meal out of home (55\%) compared to females (37\%). The youngest age group (16-25 years) was also more likely to have their lunchtime meal out of home (60\%) compared to any of the older age groups. Indeed, with increasing age group level there was a decrease in the proportion eating any meals outside of home. In terms of the energy and macronutrient content, meals eaten out of the home contained a lower proportion of protein than the diet as a whole, and more sugars and less fibre, iron and vitamins per unit energy than all foods consumed by the sample. As shown in Table 7 , those eating fewer of their foods out of home obtained a lower proportion of their food energy from fat and protein and a higher proportion from carbohydrate. This was true of both men and women, although in terms of food energy from fat the results were more striking in men. Since this data is now more than 10 years old, it would be appropriate to explore these relationships using more recent data, particularly as the practice of eating out of home has likely increased in that time, particularly 
Table 7 The mean proportion of energy from macro nutrients by sex and percentage of food energy from eating out (\%) among British adults $^{7}$

\begin{tabular}{|c|c|c|c|c|c|c|c|c|}
\hline & \multicolumn{8}{|c|}{ Percentage of food energy from eating out } \\
\hline & \multicolumn{2}{|c|}{$<20 \%$} & \multicolumn{2}{|c|}{$20 \%-40 \%$} & \multicolumn{2}{|c|}{$>40 \%$} & \multicolumn{2}{|c|}{ All consumers } \\
\hline & $\begin{array}{c}\text { Men } \\
\mathrm{N}=(271)\end{array}$ & $\begin{array}{c}\text { Women } \\
\mathrm{N}=(456)\end{array}$ & $\begin{array}{c}\text { Men } \\
\mathrm{N}=(393)\end{array}$ & $\begin{array}{c}\text { Women } \\
\mathrm{N}=(309)\end{array}$ & $\begin{array}{c}\text { Men } \\
\mathrm{N}=(362)\end{array}$ & $\begin{array}{c}\text { Women } \\
\mathrm{N}=(234)\end{array}$ & $\begin{array}{c}\text { Men } \\
\mathrm{N}=(1026)\end{array}$ & $\begin{array}{c}\text { Women } \\
\mathrm{N}=(999)\end{array}$ \\
\hline \multicolumn{9}{|c|}{ Proportion of food energy eaten out from: } \\
\hline Protein & 11.9 & 13.2 & 13.7 & 14.2 & 13.6 & 13.9 & 13.2 & 13.7 \\
\hline $\mathrm{CHO}$ & 56.1 & 46.8 & 45.8 & 43.2 & 43.5 & 43.0 & 47.7 & 44.8 \\
\hline Total fat & 33.8 & 40.5 & 41.0 & 42.9 & 43.2 & 43.3 & 39.9 & 41.9 \\
\hline
\end{tabular}

among women with a greater proportion now working out of the home compared to a decade ago.

\section{References}

$1 \mathrm{FAO} / \mathrm{WHO}$. Preparation of food based dietary guidelines. Geneva: WHO, 1998.

2 Kistemaker C, Hulshof KFAM, Bouman M. De consumptie van groepen voedingsmiddelen naar maaltijdtypering - Voedselconsumptiepeiling 1997-1998. Reportnr.V 98.809, TNO Nutrition and Food Research Institute, Zeist, the Netherlands.

3 Kistemaker C, Hulshof KFAM, Bouman M. De inname van energie en voedingsmiddelen naarmaaltijd - Voedselconsumptiepeiling
1997-1998. Reportnr.V 98.810, TNO Nutrition and Food Research Institute, Zeist, the Netherlands.

4 Lee P, Cunningham K. The Irish National Nutrition Survey (INNS). Dublin: The Irish Nutrition and Dietetic Institute, 1990. 5 Trudeau E, Kristal AR, Li S, Patterson RE. Demographic and psychosocial predictors of fruit and vegetable intakes differ: implications for dietary interventions. J. Am. Diet. Assoc. 1998; 98(12): 1412-7.

6 Gregory J, Foster K, Tyler H, Wiseman M. The Dietary and Nutritional Survey of British Adults. London: HM Stationery Office, 1990

7 MAFF (Ministry of Agriculture, Fisheries and Food). The Dietary and Nutritional Survey of British Adults: Further Analysis. London: HM Stationery Office, 1994. 